$19^{\text {th }}$ International Conference on Renewable Energies and Power Quality (ICREPQ’21)

Almeria (Spain), $28^{\text {th }}$ to $30^{\text {th }}$ July 2021

Reneumable Energy and Pomer Qualiuly, Yournal (RE\&PQJ)

ISSN 2172-038 X, Volume No.19, September 2021

\title{
Integration of the Electric Vehicle into the Electrical Grid of the Future
}

\author{
M. González-Pérez ${ }^{1}$, J.I. San Martín ${ }^{1}$, F.J. Asensio ${ }^{1}$, I. Zamora ${ }^{2}$, O. Oñederra ${ }^{2}$, G. Saldaña ${ }^{3}$ and I.J. \\ Oleagordía $^{4}$
}

\author{
${ }^{1}$ Department of Electrical Engineering \\ Engineering School of Gipuzkoa (Eibar), University of the Basque Country \\ Avda. Otaola, 29, 20600 Eibar (Spain) \\ Phone/Fax number: +34 943 033036, e-mail: mikel.gonzalezp@ehu.eus \\ ${ }^{2}$ Department of Electrical Engineering \\ Engineering School of Bilbao, University of the Basque Country \\ Pza. Ingeniero Torres Quevedo, 1, 48011 Bilbao (Spain) \\ Phone/Fax number: +34 946 014063, e-mail: inmaculada.zamora@ehu.eus \\ ${ }^{3}$ Department of Systems and Automatic Engineering \\ Engineering School of Bilbao, University of the Basque Country \\ Pza. Ingeniero Torres Quevedo, 1, 48013 Bilbao (Spain) \\ Phone number: +0034946 014310, e-mail: gaizka.saldana@ehu.eus \\ ${ }^{4}$ Department of Electronic Technology \\ Engineering School of Bilbao, University of the Basque Country \\ Pza. Ingeniero Torres Quevedo, 1, 48011 Bilbao (Spain) \\ Phone number: +0034 946 014304, e-mail: ij.oleagordia@ehu.eus
}

\begin{abstract}
Environmental issues are a major concern in society. To solve them, new technologies have appeared in the las few years, such as Renewable Energy Sources (RES) or Electric Vehicles (EVs). Nevertheless, all these technologies have a huge impact in the Electric System, and especially, in the electric grid, due to their technical characteristics. In this sense, the grid needs to evolve to assume the new electric scenario. In this context, this paper is focused on summarizing how the grid should evolve to correctly integrate these new elements into de system with a special focus on EVs, as they will be the ones with the greatest affection on the load profiles. Hence, how to integrate EVs into the grid considering charging profiles will be explained in order to design the electric grid of the future.
\end{abstract}

Key words. EV integration, charging profiles, Smart Grids, V2G.

\section{Introduction}

Greenhouse gas emissions are the major cause of climate change and global warming. The apparition of unpredictable and extreme meteorological phenomena, ocean acidification, loss of biodiversity, land degradation, etc. can be found among their effects [1], [2]. Therefore, it is essential to make an energy transition towards a more sustainable and carbon-free model.

One of the ways to achieve this goal relies on the replacement of traditional sources of electrical energy with
Renewable Energy Sources (RES) [3]. Likewise, it is equally important to electrify sectors that depend on fossil fuels. In this sense, the electrification of road transportation will play an important role [4]-[6]. Electric Vehicles (EVs) improve air quality of cities, facilitate RES integration, have higher efficiency than Internal Combustion Engine Vehicles (ICEVs), have lower maintenance due to fewer mechanical elements, enable Electrical Energy Storage (EES) integration, etc. [7], [8].

Apart from these environmental and technical advantages, EVs are gaining importance due to the following factors [9], [10]:

1) Reduction of EV prices (especially due to the reduction in the price of batteries).

2) Increase of the number of charging points.

3) Public perceptions and subsidies.

4) Favourable regulation.

5) Increase of social environmental awareness.

It should be noted that in order to achieve a massive integration of the $\mathrm{EV}$, electric grid must also be taken into account [11]. Otherwise, an uncontrolled integration would affect the power quality and would bring many associated problems like [12], [13]:

1) Congestion of the distribution networks.

2) Power losses. 
3) Compromising the safety and reliability of the power system.

4) Frequency and voltage deviation.

5) Harmonic distortion.

This inefficient management of recharging would imply an increase in the cost of energy, for both the end user and the owners of the electricity system infrastructure.

In case the EV charging is carried out in a controlled manner, it would be beneficial for the power grid, favouring proper management of power flows, minimizing power losses, and avoiding unnecessary investment in new infrastructure [14].

Considering that EVs remain parked around $96 \%$ of the time, the Vehicle-to-Grid (V2G) concept is starting to make sense [15]. V2G is an EV charging strategy with an integrated view of power, information and money flows between EV owners, the grid, and, where applicable, the aggregator.

It aims to use the energy stored in EV batteries to support the grid. To do this, EVs are charged during off-peak hours when electricity is cheap, and that energy is returned to the grid when it is needed due to technical reasons [16], [17].

As a consequence of the fluctuating nature of RES and their increasing integration into the power system, grid ancillary services are becoming more and more important. In this sense, $\mathrm{V} 2 \mathrm{G}$ is seen as one of the possible technoeconomic solutions, since the natural gas power plants that have traditionally been used for this task, as they are working less and less hours, are becoming less profitable [18].

\section{Evolution of the electric grid}

Historically, power grids have been a key component of social and economic development. Nowadays, the world is facing an energy transition, and once again, the power grid is at the spotlight, as it is the integrating element of the new ways of generating and consuming electricity.

The power grid is the core of the electric system. Therefore, while new agents are being integrated into the system, the grid must be adapted to the new needs and characteristics. Thus, to make the penetration of RES and the integration of EVs possible, the grid must be developed oriented towards digitization and automation. This scenario is favorable for the development of Smart Grids (SGs) [19], [20].

SGs integrate in an intelligent and efficient way the actions of energy producers, consumers, and prosumers, optimizing the production, distribution, and consumption of electricity. They are characterized by [19], [20]:

1) Enabling controlled bi-directional flow of electricity and information.

2) Enabling active demand management in real time.

3) Being fully sensorized, monitored and automated.
4) Having a decentralized architecture and being autonomous and intelligent, with adaptive protections.

5) Allowing the insertion of distributed generation (DG).

6) Managing resources efficiently and focusing on Power Quality (PQ).

All this makes SGs an essential part of the smart cities of the future, where the end users will no longer be just consumers but will become active agents that participate and interact with the grid.

In summary, Smart Cities will enable the coordinated and efficient collaboration of all infrastructures (energy, mobility, water, etc.) in a Smart Environment. Thanks to this, individual objectives will be unified at the physical infrastructure level to achieve an overall benefit that goes beyond the individual level. This overall benefit encompasses energy efficiency, sustainability, quality of life, safety and security, system resilience, etc. [20]-[22]

In this scenario, new agents such as Demand Response (to shift demand in a controlled manner), Electric Vehicles and their aggregators (as the effect of a single $\mathrm{EV}$ is negligible, the aggregator joins a group to have a real effect in the grid), Smart Meters (to reliably know the behavior of demand), Smart Homes (computerized homes to efficiently manage energy) and Smart Consumers (consumers who are self-aware of their actions), are going to emerge [20]-[22].

With the proliferation of DG and V2G services, more and more Virtual Power Plants (VPP) will be deployed. VPPs are systems composed of different DER and loads that operate together and can behave as a power plant or as a load. They are controlled by an aggregator and provide higher efficiency and more flexibility than the actual network configurations [23].

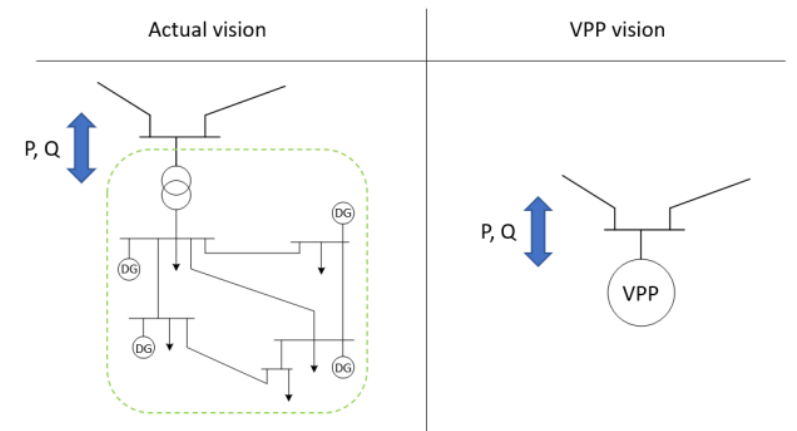

Fig. 1. System Operator's current vision of the DG vs. System Operator's vision under the VPP concept.

In this scenario, it is crucial to manage the energy in the most efficient way, not only in a macro scale, but also locally. In this sense, the Demand Side Management (DSM) is seen as a potential solution. In the DSM, the efficiency is obtained through a more active participation of the costumers, offering them more beneficial solutions. To achieve a proper implementation of DSM, it is essential to develop automation technologies and communication infrastructures [24]. 
In a near future, electric grids will not be a passive element just for carrying electricity as they have traditionally been. In this sense, they will be intelligent elements capable of real-time decision making and involving many different agents. However, to develop this electric grid of the future, it is necessary to know how the participants will affect it.

In this new situation, how the EV will be integrated into the grid plays a key role.

\section{EV integration into the grid}

In order to achieve the environmental objectives defined by the European Union (EU) [25], a huge insertion of EVs will be necessary. Considering the amount of energy they will demand, it is assumable that they will become one of the agents of the future that will most affect the traditional electricity consumption profiles.

But nowadays, there is almost no data available of how these EV charging profiles are. This is because the amount of operational EVs is still small and because the ones that are operational, are not monitored for this kind of studies.

So, in pursuit of solving this lack of information, scientific community is making previsions based on available information in databases. These databases generally include the following [26]:

1) Number of vehicles per home.

2) Departing and arrival time of vehicles.

3) Average travelling distance.

4) Differentiation between working days and holydays.

5) Driving patterns.

To extrapolate this data to EVs, some assumptions should be made. For example, it should be assumed that the behavior of EVs (arrival and departing time, travelling purpose, etc.) will be the same as the ICEVs. It should also be considered that while EVs are at home they will be plugged to the grid.

With this information and assumptions, it can be estimated how long EVs would be parked, how much energy they would consume, at which time they will be connected to the grid, etc. Considering all this information, EV charging profiles can be predicted [27], [28].

To perform this, the probability distribution of vehicle arrival times must first be obtained. Next, it is necessary to obtain the probability distribution of vehicle departure. Once these two curves are obtained, the times during which the EVs remain connected to the network can be obtained.

Then, the distribution of the distances traveled by the users is obtained. With this information, the energy expenditure during the trips can be estimated, and it can be deduced which level of the State of Charge (SoC) is available when plugging in the EVs. Consequently, it can be estimated how the demand profile of the EVs will be like [29], [30].

This charging profiles may significantly vary from region to region. It is important to highlight the relevance of the social-demographic and cultural habits that will ultimately determinate the driving patterns, and hence, the EV charging profiles. In the same way, the patterns may also vary from winter to summer, from residential to commercial areas, from labor days to weekdays, etc. [31], [32].

\section{Conclusions}

The electric system paradigm is changing. Intermittent RES and DG are appearing. New consumption models are being introduced, such as prosumers, which can act as energy generators or consumers. In addition, the electrification process that many sectors are facing, will drastically increase the electrical demand. All this will completely change power flows through the electric grids, and hence, the network will need to evolve. This modernization will be achieved through the digitalization and automation of all agents participating in the electric system, giving rise to smart grids, VPP, DSM, etc.

However, to design the grid of the future, it is essential to know how the demand trends will be, especially, the ones that will most affect the power flows, such as EV charging profiles.

Mostly, these profiles are obtained through statistical analysis of databases, and they may vary depending on the season, geographical site, demography, cultural habits, weekdays and holydays, residential and commercial areas, travelling purposes, etc.

Understanding them will be a key factor for EV integration and for de development of the electric grid of the future.

\section{Acknowledgement}

The authors acknowledge the support of Spanish Ministry of Universities (FPU19/01902), Basque Government (ELKARTEK KK-2020/00050 and GISEL Research Group IT1191-19, PIBA_2019_1_0098) and the University of the Basque Country UPV/EHU (COLAB19).

\section{References}

[1] Y. Li et al, "The role of freshwater eutrophication in greenhouse gas emissions: A review," Sci. Total Environ., vol. 768, pp. 144582, 2021. Available: https://www.sciencedirect.com/science/article/pii/S0048969720 381134. DOI: https://doi.org/10.1016/j.scitotenv.2020.144582.

[2] IPCC, Intergovernmental Panel on Climate Change, "Special Report on the Ocean and Cryosphere in a Changing Climate," 2019. Available: https://www.ipcc.ch/srocc/. 
[3] IRENA, International Renewable Energy Agency, "Energy Transition," $2018 . \quad$ Available: https://www.irena.org/energytransition.

[4] P. G. Pereirinha et al, "Main Trends and Challenges in Road Transportation Electrification," Transportation Research Procedia, vol. 33, pp. 235-242, 2018. Available: https://www.sciencedirect.com/science/article/pii/S23521465183 02527. DOI: https://doi.org/10.1016/j.trpro.2018.10.096.

[5] S. P. Holland et al, "The environmental benefits of transportation electrification: Urban buses," Energy Policy, vol. 148, pp. 111921, 2021. Available: https://www.sciencedirect.com/science/article/pii/S03014215203 06327. DOI: https://doi.org/10.1016/j.enpol.2020.111921.

[6] P. A. DeCotis, "The Rise of Transportation Electrification," Natural Gas \& Electricity, vol. 36, (6), pp. 9-15, 2020. Available: https://doi.org/10.1002/gas.22153. https://doi.org/10.1002/gas.22153.

[7] E. A. Nanaki, "Chapter 2 - Electric vehicles," Electric Vehicles for Smart Cities, pp. 13-49, 2021. Available: https://www.sciencedirect.com/science/article/pii/B97801281580 1200006X. DOI: https://doi.org/10.1016/B978-0-12-8158012.00006-X.

[8] G. Saldaña et al, "Electric Vehicle into the Grid: Charging Methodologies Aimed at Providing Ancillary Services Considering Battery Degradation," Energies, vol. 12, (12), 2019. . DOI: $10.3390 /$ en12122443.

[9] E. A. Nanaki, "Chapter 5 - Climate change mitigation and electric vehicles," Electric Vehicles for Smart Cities, pp. 141180, 2021.2 Available: https://www.sciencedirect.com/science/article/pii/B97801281580 12000022. DOI: https://doi.org/10.1016/B978-0-12-8158012.00002-2.

[10] I. E. A. IEA, "Promoting vehicle efficiency and electrification through stimulus packages," 2020. Available: https://www.iea.org/articles/promoting-vehicle-efficiency-andelectrification-through-stimulus-packages.

[11] A. Annaswamy, "IEEE Vision for Smart Grid Control: 2030 and Beyond Roadmap," IEEE Vision for Smart Grid Control: 2030 and Beyond Roadmap, pp. 1-12, 2013. DOI: 10.1109/IEEESTD.2013.6648362.

[12] M. Nour et al, "Impacts of plug-in electric vehicles charging on low voltage distribution network," in - 2018 International Conference on Innovative Trends in Computer Engineering (ITCE), 2018. DOI: 10.1109/ITCE.2018.8316650.

[13] H. E. V. Ayala and N. G. Barriga, "Study of the impact of electric vehicles fleets in $\mathrm{HV}$ electric power grids based on an uncontrolled charging strategy," in - 2017 IEEE International Autumn Meeting on Power, Electronics and Computing (ROPEC), 2017. DOI: 10.1109/ROPEC.2017.8261680.

[14] K. M. Tan, V. K. Ramachandaramurthy and J. Y. Yong, "Integration of electric vehicles in smart grid: A review on vehicle to grid technologies and optimization techniques," Renewable and Sustainable Energy Reviews, vol. 53, pp. 720732, $2016 . \quad$ Available: https://www.sciencedirect.com/science/article/pii/S13640321150 0982X. DOI: https://doi.org/10.1016/j.rser.2015.09.012.

[15] W. Kempton and J. Tomić, "Vehicle-to-grid power implementation: From stabilizing the grid to supporting large- scale renewable energy," J. Power Sources, vol. 144, (1), pp 280-294, $2005 . \quad$ Available: https://www.sciencedirect.com/science/article/pii/S0378775305 000212. DOI: https://doi.org/10.1016/j.jpowsour.2004.12.022.

[16] C. Zhou et al, "Economic analysis of auxiliary service by V2G: City comparison cases," Energy Reports, vol. 6, pp. 509514, $2020 . \quad$ Available: https://www.sciencedirect.com/science/article/pii/S2352484720 316310. DOI: https://doi.org/10.1016/j.egyr.2020.11.205.

[17] X. Li et al, "A cost-benefit analysis of V2G electric vehicles supporting peak shaving in Shanghai," Electr. Power Syst. Res., vol. 179, pp. 106058, 2020. Available: https://www.sciencedirect.com/science/article/pii/S0378779619 303773. DOI: https://doi.org/10.1016/j.epsr.2019.106058.

[18] B. Bibak and H. Tekiner-Moğulkoç, "A comprehensive analysis of Vehicle to Grid (V2G) systems and scholarly literature on the application of such systems," Renewable Energy Focus, vol. 36, pp. 1-20, 2021. Available: https://www.sciencedirect.com/science/article/pii/S1755008420 300533. DOI: https://doi.org/10.1016/j.ref.2020.10.001.

[19] N. Hadjsaid et al, Smartgrids. 2012. Available: https://ehu.on.worldcat.org/oclc/929347740.

[20] A. Colmenar Santos et al, Generación Distribuida, Autoconsumo Y Redes Inteligentes. (1st ed.) Madrid: UNED, 2015.

[21] S. Borlase, Smart Grids. Advanced Technologies and Solutions. (2nd ed.) CRC Press, 2018.

[22] L. Hernandez Callejo, Microredes Eléctricas. Integración De Generación Renovable Distribuida, Almacenamiento Distribuido, E Inteligencia. (1st ed.) Garceta publicaciones, S.L., 2019.

[23] N. 1. Jenkins, J. 1. Ekanayake and G. Strbac, Distributed Generation. $2010 \quad$ Available: https://ehu.on.worldcat.org/oclc/761013971.

[24] E. Sarker et al, "Progress on the demand side management in smart grid and optimization approaches," Int. J. Energy Res., vol. 45, (1), pp. 36-64, 2021. Available: https://doi.org/10.1002/er.5631. https://doi.org/10.1002/er.5631.

[25] STRIA, Strategic Transport Research and Innovation Agenda, TRIMIS, Transport Research and Innovation Monitoring and Information System and E. U. EU, "STRIA Roadmap on Transport Electrification (ELT)," 2020. Available: https://trimis.ec.europa.eu/.

[26] E. Xydas et al, "A data-driven approach for characterising the charging demand of electric vehicles: A UK case study," Appl. Energy, vol. 162, pp. 763-771, 2016. Available: https://www.sciencedirect.com/science/article/pii/S0306261915 013938. DOI: https://doi.org/10.1016/j.apenergy.2015.10.151.

[27] J. Schäuble et al, "Generating electric vehicle load profiles from empirical data of three EV fleets in Southwest Germany," J. Clean. Prod., vol. 150, pp. 253-266, 2017. Available: https://www.sciencedirect.com/science/article/pii/S0959652617 303761. DOI: https://doi.org/10.1016/j.jclepro.2017.02.150.

[28] C. B. Harris and M. E. Webber, "An empirically-validated methodology to simulate electricity demand for electric vehicle charging," Appl. Energy, vol. 126, pp. 172-181, 2014. 
Available:

https://www.sciencedirect.com/science/article/pii/S03062619140

03183. DOI: https://doi.org/10.1016/j.apenergy.2014.03.078.

[29] A. Ahmadian, M. Sedghi and M. Aliakbar-Golkar, "Stochastic modeling of plug-in electric vehicles load demand in residential grids considering nonlinear battery charge characteristic," in - 2015 20th Conference on Electrical Power Distribution Networks Conference (EPDC), 2015. DOI: 10.1109/EPDC.2015.7330467.

[30] E. Pashajavid and M. A. Golkar, "Charging of plug-in electric vehicles: Stochastic modelling of load demand within domestic grids," in - 20th Iranian Conference on Electrical Engineering (ICEE2012), 2012. DOI: 10.1109/IranianCEE.2012.6292415.

[31] J. Zhang et al, "Daily electric vehicle charging load profiles considering demographics of vehicle users," Appl. Energy, vol. 274, pp. 115063, 2020. Available: https://www.sciencedirect.com/science/article/pii/S03062619203 05754. DOI: https://doi.org/10.1016/j.apenergy.2020.115063.

[32] Q. Xing et al, "Charging Demand Forecasting Model for Electric Vehicles Based on Online Ride-Hailing Trip Data," IEEE Access, vol. 7, pp. 137390-137409, 2019. DOI 10.1109/ACCESS.2019.2940597. 